\title{
Study of serum pentraxin 3 level in patients with diabetic nephropathy
}

\author{
Alaaeldin Abdelsalam Dawood', Mai Ashraf Kamel', Thoria Ahmed Omar ${ }^{1}$ and \\ Ahmed Ahmed Mohammed Agaba ${ }^{2^{*}}$ (D)
}

\begin{abstract}
Background: Pentraxin 3 (PTX3), a member of a superfamily of conserved proteins called pentraxins. PTX3 and Creactive protein (CRP) are members of this family and play an important role in the innate immune system. PTX3 is classified as a long pentraxin, while CRP is a short pentraxin. PTX3 is reported to be a vascular inflammatory marker providing prognostic information of vasculopathy, such as diabetic nephropathy (DN). The purpose of this study is to evaluate the association between serum PTX3 concentrations and the development and/or progression of DN. A total number of 66 patients with type 2 diabetes mellitus (T2DM) and 22 healthy subjects were enrolled in this study. Patients with T2DM were divided, according to the levels of urinary albumin/creatinine ratio (UACR), into three groups: normoalbuminuric, microalbuminuric, and macroalbuminuric groups. Serum PTX3 and high-sensitivity C-reactive protein (hs-CRP) concentrations were determined using ELISA kits.
\end{abstract}

Results: Serum PTX3 and hs-CRP concentrations were significantly higher in patients with T2DM compared with the controls. Furthermore, serum PTX3 concentrations were significantly higher in macroalbuminuric patients than in microalbuminuric patients $(P<0.001)$ and also were significantly higher in microalbuminuric patients than in normoalbuminuric patients $(P<0.001)$. However, there were no significant differences between controls and T2DM patients with normoalbuminuria regarding serum PTX3 concentrations $(P>0.05)$. Moreover, like PTX3, hs-CRP concentrations were higher in microalbuminuric patients than in normoalbuminuric patients $(P<0.05)$, and also, there were no significant differences between controls and T2DM patients with normoalbuminuria regarding hsCRP concentrations $(P>0.05)$. But, unlike PTX3, there were no significant differences between macroalbuminuric and microalbuminuric patients regarding hs-CRP concentrations $(P>0.05)$.

Conclusions: Serum PTX3 is positively associated with DN development and progression, and may be a more accurate predictor of DN development than hs-CRP as it can discriminate between macroalbuminuric and microalbuminuric DN patients, while hs-CRP cannot.

Keywords: Diabetes mellitus, Diabetic nephropathy, Pentraxin 3

\section{Background}

Diabetes mellitus (DM) is a chronic non-communicable systemic disease characterized by hyperglycemia and considered as a major public health problem [1]. It is considered one of the most important causes of increased morbidity and mortality all over the world as it

\footnotetext{
*Correspondence: ah_agaba@yahoo.com

${ }^{2}$ Internal Medicine Department, Ahmed Maher Teaching Hospital, Cairo, Egypt

Full list of author information is available at the end of the article
}

has several microvascular and macrovascular complications [2].

The extent of systemic inflammatory reaction in DM has been an important cause of its complications [3]. The clinically evident chronic complications are cardiac disease, nephropathy, neuropathy, retinopathy, and foot ulcers [2].

One of the most devastating microvascular complications of DM is DN which can lead to end-stage renal disease [4]. People with diabetes have a higher risk for 
developing nephropathy than those without diabetes [5]. $\mathrm{DN}$ is a clinical syndrome characterized by the occurrence of persistent microalbuminuria in concomitance with insulin- or non-insulin-dependent diabetes. It is diagnosed by persistent increment of albumin or protein in urine when there is no any other known renal disease [6].

In this regard, several studies have reported that T2DM is associated with increased plasma concentrations of acute-phase biomarkers, including hs-CRP, which is related to the innate immune response and inflammation [7]. There are several studies showing the relationship between $\mathrm{DM}$ and $\mathrm{DN}$, and classical markers of inflammation like hs-CRP and fibrinogen. But levels of these markers may be correlated with many factors other than inflammation. So, there is a need for more specific markers related to DN [8].

PTX3 is an acute-phase reactant characterized by a cyclic multimeric structure. PTX3 is a long pentraxin and produced by peripheral tissues including endothelial cells, mononuclear phagocytes, dendritic cells, neutrophils, smooth muscle cells, fibroblasts, adipocytes, renal fibroblasts, and proximal tubular cells and reflects impaired vascular endothelial function. In contrast, CRP is mainly produced by hepatocytes and is predominantly under the transcriptional control of the cytokine interleukin-6 (IL-6) [9].

PTX3 inhibits angiogenesis, promotes restenosis, and increases advanced atherosclerotic lesions typically by inhibiting the fibroblast growth factor reaction of angiogenesis [10]. PTX3 has been shown to be a sensitive biomarker of localized inflammatory reactions and innate immunity of cardiovascular and renal diseases [11].

This study aims to explore the association between serum PTX3 levels and the development and/or progression of $\mathrm{DN}$ in $\mathrm{T} 2 \mathrm{DM}$ patients.

\section{Methods}

This retrospective case-control study was carried out in the outpatient clinic of internal medicine at Ahmed Maher Teaching Hospital from December 2018 to June 2019. The study included 66 patients with type 2 diabetes mellitus and 22 healthy individuals aged from 41 to 75 years; the disease duration ranged from 6 to 22 years.

\section{Study design}

The selected subjects were divided into three groups:

- Group I (control group): 22 subjects with no history, clinical symptoms, nor laboratory evidence of DM.

- Group II (diabetic without DN): 22 patients with T2DM without DN.

- Group III (DN group): 44 patients with T2DM and $\mathrm{DN}$, who are further subdivided according to UACR into 2 subgroups:
- Group III-A: 22 patients with microalbuminuria (UACR = 30-300 $\mathrm{mg}$ albumin/g creatinine).

- Group III-B: 22 patients with macroalbuminuria (UACR < $300 \mathrm{mg}$ albumin/g creatinine).

\section{Inclusion criteria}

All patients had T2DM.

\section{Exclusion criteria}

Type 1 DM, primary kidney disease, coronary heart diseases, past history of stroke, past history of malignancy, end-stage renal failure, chronic liver disease, acute and chronic viral or bacterial infections, and immunological disorders.

\section{Methodology}

The following was done for patients and control after consent and explanation of the procedures:

1- Full history taking including the following: name, age, sex, duration of diabetes, anti-diabetic treatment, cardiovascular disease, evidence of $\mathrm{DN}$, hypertension and its treatment, drug history, and smoking.

2- Clinical examination including the following items:

- Assessment of body mass index (BMI).

- Assessment of systolic blood pressure (SBP) and diastolic blood pressure (DBP).

All patients were informed about the study, and consents were taken from all patients before taking the blood samples.

3- Routine investigations:

Fasting blood glucose (FBG), $2 \mathrm{~h}$ postprandial blood glucose (2hPPBG), $\mathrm{HbA}_{1} \mathrm{c}$, total cholesterol, triglycerides (TGs), high-density lipoprotein (HDL), low-density lipoprotein (LDL), serum creatinine, UACR, serum albumin, Alanine transaminase (ALT), Aspartate transaminase (AST), serum hsCRP, and serum PTX3.

Blood samples were obtained at the morning after $8 \mathrm{~h}$ fasting for FBG, $2 \mathrm{~h}$ after breakfast for $2 \mathrm{hPPBG}$, and $12 \mathrm{~h}$ fasting for estimation of other parameters. Blood was aspirated into three plastic tubes: the first contained k-EDTA for $\mathrm{HbA}_{1} \mathrm{c}$ measurement, and the second contained no additive for serum separation. Lipid profile, ALT, AST, and creatinine were estimated immediately within a suitable time. Another part of serum stored at $-80^{\circ} \mathrm{C}$ until assay of hs-CRP, the third tube contained K-EDTA centrifuged for $15 \mathrm{~min}$ at $1000 \times \mathrm{g}$ within $30 \mathrm{~min}$ of collection, and plasma separated and stored at $-80^{\circ} \mathrm{C}$ until assay of PTX3.

Human PTX3 was estimated by solid-phase enzyme-linked immunosorbent assay (ELISA) technique using human pentraxin 3/TSG-14 ELISA kits. 


\section{Statistical methodology}

Results were collected, tabulated, and statistically analyzed by SPSS (Statistical Package for Social Science) version 22 on a personal computer.

Two types of statistics were done:

1- Descriptive: percentage (\%) and mean and standard deviation (SD).

2- Analytical:

a) Student's $t$ test: it is a single test used to collectively indicate the presence of any significant difference between two groups for a normally distributed quantitative variable.

b) ANOVA ( $F$ test): a one-way analysis of variance (ANOVA) is a single test used to collectively indicate the presence of any significant difference between several groups for a normally distributed quantitative variable.

c) Post hoc test: it is used after one-way ANOVA ( $F$ test) to show any significant difference between the individual groups.

d) Chi-square $\left(x^{2}\right)$ test: it is used to compare between two groups or more regarding one qualitative variable.

e) Pearson's correlation coefficient $(r)$ : a test that was used for correlating data.

f) Probability test ( $P$ value):

- $P$ value $<0.05$ was considered significant.

- $P$ value $<0.001$ was considered highly significant.

- $P$ value $>0.05$ was considered nonsignificant.

\section{Results}

\section{Demographic characteristics of patients with T2DM and} controls

As presented in Table 1, the mean age for groups I, II, III-A, and III-B was $52.64 \pm 6.33,54.68 \pm 6.68,57.36 \pm$ 6.71 , and $65.95 \pm 4.24$ years, respectively. These results demonstrate that patients with DN had significantly higher ages as compared to the control and diabetic without DN groups. This study also showed that the mean value of BMI for groups I, II, III-A, and III-B was $24.17 \pm 1.44,25.35 \pm 1.32,26.69 \pm 1.92$, and $27.42 \pm$ 1.84 , respectively. These results demonstrate that there is high significance of $\mathrm{BMI}$ in the DN groups than in the control and diabetic without DN groups $(P<0.001)$.

Furthermore, the mean values of duration of DM, SBP, and DBP were significantly different between the four groups $(P<0.001, P=0.004$, and $P<0.001$, respectively).
However, the gender and smoking were not significantly different between the studied groups $(P=0.819$ and $P=0.580$, respectively).

\section{Laboratory characteristics of patients with T2DM and controls}

This study also revealed that there was a highly significant correlation between glycemic control and development of DN, as the mean values of HbA1c, FBG, and 2hPPBG were significantly higher in the DN groups than in the control and diabetic without DN groups. The mean value of HbA1c for groups I, II, III-A, and III-B was $5.2 \pm 0.2,8.8 \pm 1.9,8.7 \pm 1.7$, and $9.4 \pm 1.4 \mathrm{mg} / \mathrm{dl}$, respectively. Also, the mean value of FBG for groups I, II, III-A, and III-B was $83.95 \pm 11.19,138.14 \pm 14.36$, $164.68 \pm 14.34$, and $172.91 \pm 20.83 \mathrm{mg} / \mathrm{dl}$, respectively. Moreover, the mean value of $2 \mathrm{hPPBG}$ for groups I, II, III-A, and III-B was $127.68 \pm 6.32,173.59 \pm 15.57$, $206.73 \pm 33.32$, and $304.86 \pm 72.88 \mathrm{mg} / \mathrm{dl}$, respectively.

Regarding kidney function, this study showed that there was a highly significant association between serum creatinine $(P<0.001)$ and also UACR $(P<0.001)$, and development of $\mathrm{DN}$ as they were elevated in the $\mathrm{DN}$ groups more than in the control and diabetic without DN groups.

According to liver enzymes and serum albumin, there was a highly significant association between $\mathrm{DN}$ and serum albumin level as albumin was decreased in the DN groups more than in the control and diabetic without DN groups $(P<0.001)$. But, there was no association between liver enzymes and the development of $\mathrm{DN}$, as there was no significant association between the studied groups regarding AST $(P=0.439)$ and ALT $(P=0.248)$.

Regarding dyslipidemia, this study revealed that there was a significant correlation between serum triglycerides and severity of the $\mathrm{DN}$ as the mean value of TGs for groups I, II, III-A, and III-B was $117.5 \pm 35.0,152.7 \pm$ 29.0, $137.8 \pm 43.9$, and $157.1 \pm 23.5 \mathrm{mg} / \mathrm{dl}$, respectively. Moreover, there was no significant association between the studied groups regarding serum cholesterol $(P=$ $0.082)$, HDL $(P=0.349)$, and LDL $(P=0.137)$.

\section{Association between DN development and values of serum PTX3 and hs-CRP}

As shown in Table 2, the mean value of PTX3 in the DN groups was significantly higher than in the control and diabetic without DN groups $(P<0.001)$. Moreover, serum PTX3 concentrations in the macroalbuminuric group were higher than in the microalbuminuric group. But, there is no significant difference between the control and diabetic without $\mathrm{DN}$ groups $(P=0.13)$.

As regards serum hs-CRP, the mean value of hs-CRP in the DN groups was significantly higher than in the control and diabetic without DN groups $(P<0.001)$. 


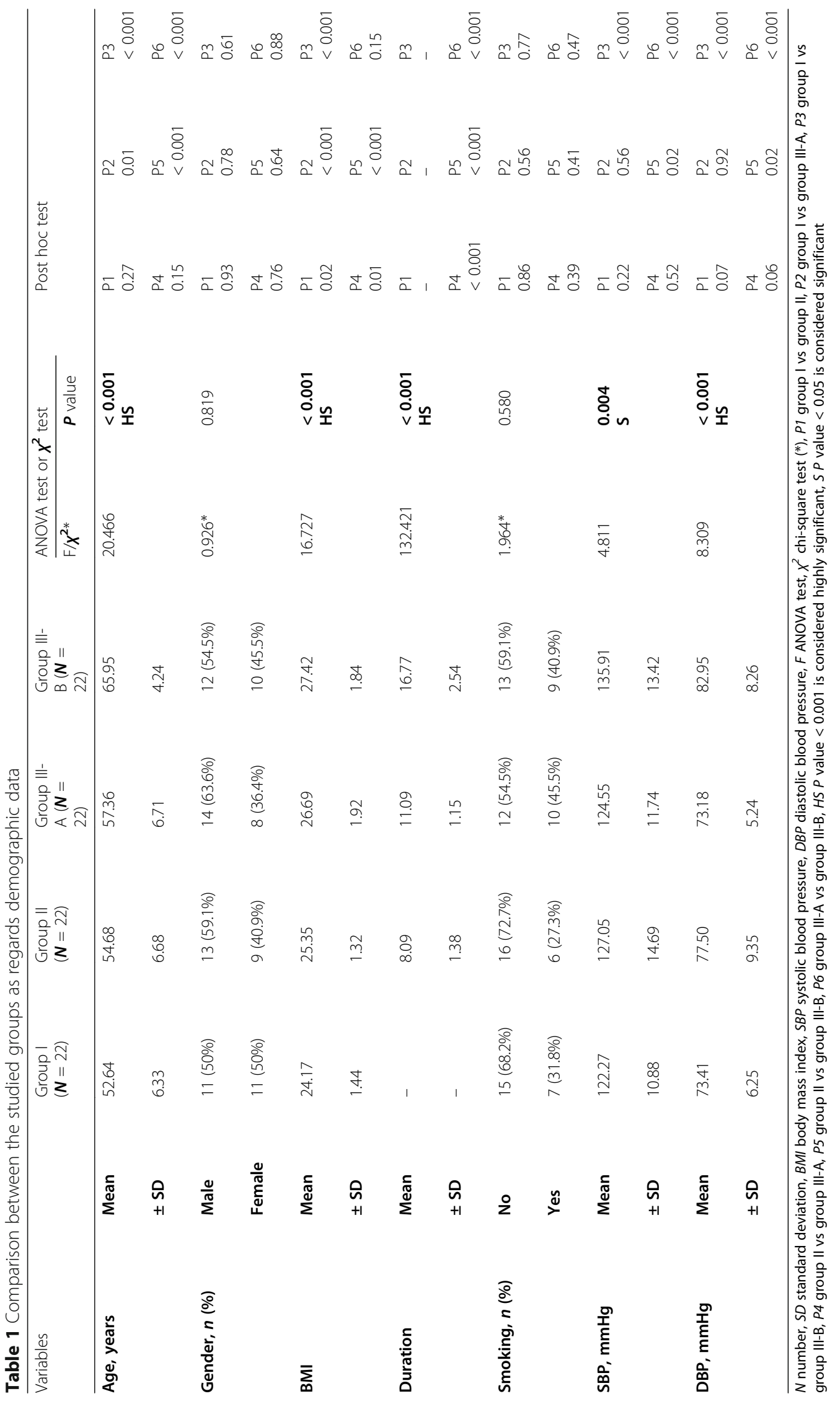


Table 2 Comparison between the studied groups as regards PTX3 and hs-CRP

\begin{tabular}{|c|c|c|c|c|c|c|c|c|c|c|}
\hline \multirow[t]{2}{*}{ Variables } & & \multirow{2}{*}{$\begin{array}{l}\text { Group } \\
\text { I ( } \boldsymbol{N}= \\
22)\end{array}$} & \multirow{2}{*}{$\begin{array}{l}\text { Group } \\
\|(\boldsymbol{N}= \\
22)\end{array}$} & \multirow{2}{*}{$\begin{array}{l}\text { Group } \\
\text { III-A ( } \boldsymbol{N} \\
=22)\end{array}$} & \multirow{2}{*}{$\begin{array}{l}\text { Group } \\
\text { III-B }(\boldsymbol{N} \\
=22)\end{array}$} & \multicolumn{2}{|c|}{ ANOVA test } & \multirow{2}{*}{\multicolumn{2}{|c|}{ Post hoc test }} & \multirow[t]{2}{*}{ 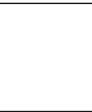 } \\
\hline & & & & & & $F$ & $\boldsymbol{P}$ value & & & \\
\hline \multirow[t]{2}{*}{ PTX3 (ng/ml) } & Mean & 1.50 & 2.27 & 8.15 & 14.26 & 282.726 & $\begin{array}{l}<0.001 \\
\text { HS }\end{array}$ & $\begin{array}{l}\text { P1 } \\
0.13\end{array}$ & $\begin{array}{l}P 2 \\
<0.001\end{array}$ & $\begin{array}{l}P 3 \\
<0.001\end{array}$ \\
\hline & $\pm \mathrm{SD}$ & 0.35 & 0.32 & 2.08 & 2.53 & & & $\begin{array}{l}\text { P4 } \\
<0.001\end{array}$ & $\begin{array}{l}\text { P5 } \\
<0.001\end{array}$ & $\begin{array}{l}\text { P6 } \\
<0.001\end{array}$ \\
\hline \multirow[t]{2}{*}{ hs-CRP (mg/l) } & Mean & 2.61 & 2.75 & 3.14 & 3.08 & 12.840 & $\begin{array}{l}<0.001 \\
\text { HS }\end{array}$ & $\begin{array}{l}\text { P1 } \\
0.16\end{array}$ & $\begin{array}{l}P 2 \\
<0.001\end{array}$ & $\begin{array}{l}\text { P3 } \\
<0.001\end{array}$ \\
\hline & \pm SD & 0.34 & 0.35 & 0.28 & 0.38 & & & $\begin{array}{l}\text { P4 } \\
<0.001\end{array}$ & $\begin{array}{l}\text { P5 } \\
0.002\end{array}$ & $\begin{array}{l}\text { P6 } \\
0.52\end{array}$ \\
\hline
\end{tabular}

But, there is no significant difference between the macroalbuminuric and microalbuminuric groups $(P=$ 0.52 ), and also no significant difference between the control and diabetic without DN groups regarding serum hs-CRP $(P=0.16)$.
The association of serum PTX3 concentrations with other clinical characteristics

Pearson's correlation test reveals that there is a positive correlation between serum PTX3 and UACR in all diabetic groups (Figs. 1, 2, and 3). Our results also reveal

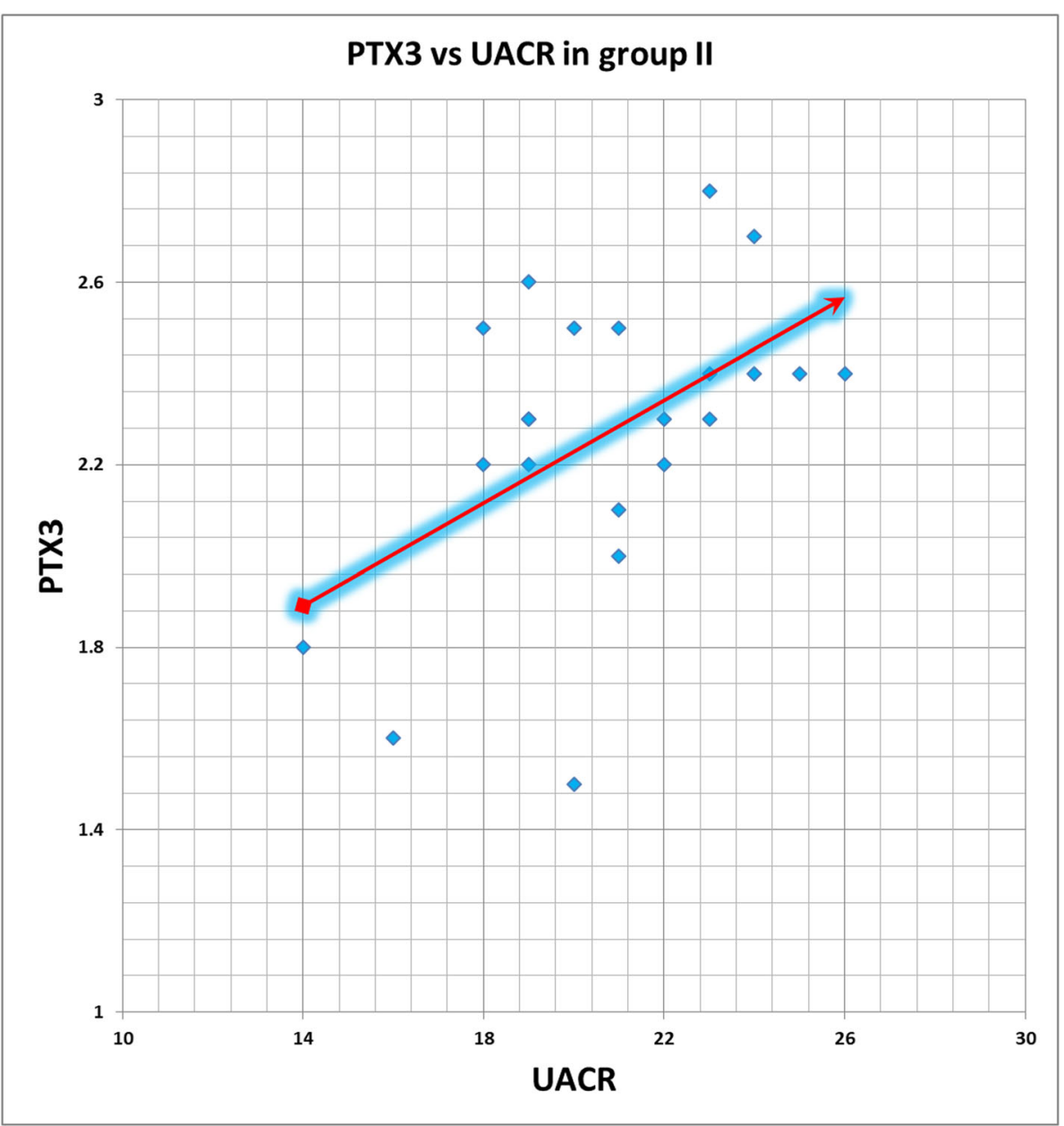

Fig. 1 Positive correlation between PTX3 vs UACR in group ॥ 


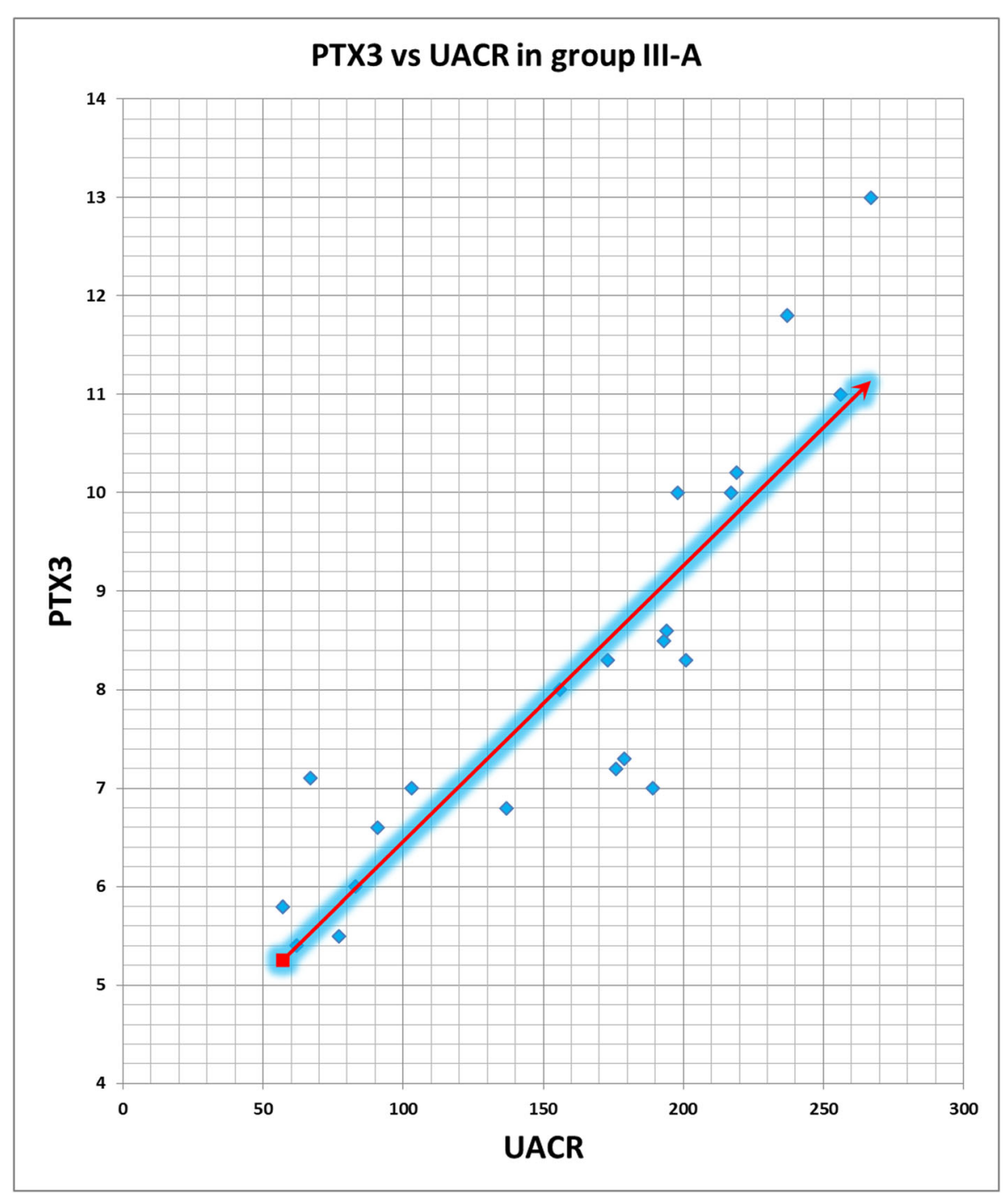

Fig. 2 Positive correlation between PTX3 vs UACR in group III-A

that there is a positive correlation between serum PTX3 and serum creatinine and another negative correlation between serum PTX3 and serum albumin in the DN groups (groups III-A and III-B).

\section{Discussion}

DN represents a major cause of chronic kidney disease (CKD) all over the world. Thus, there is a need to implement effective strategies being able to prevent $\mathrm{DN}$ and to identify specific and early predictors. The etiology of $\mathrm{DN}$ is multifactorial, but reported risk factors include increased duration of DM, as well as severity of hypertension and hyperglycemia [12].

Dyslipidemia is a powerful risk factor for atherosclerosis and related disorders such as ischemic heart disease, cerebrovascular diseases, renal disease, and retinal atherosclerosis [13].
This study showed that patients with DN had significantly higher ages as compared to the control group and the diabetic without DN group. These results are in agreement with Wang et al. [12], unlike Abu Seman et al.'s [14] study which showed that there was no significant age difference between groups.

However, this study also showed that there was no sex effect on the development of DN in diabetic patients. These results were observed also by Wang et al. [12] and Abu Seman et al. [14]. Like Sjöberg et al. [15], this study also showed that there is no role for smoking in the development of DN.

Moreover, this study showed that the DN groups had higher values of BMI than the control and diabetic without DN groups. This is in agreement with Porrini et al. [16] who mentioned that obesity with a BMI of $>30 \mathrm{~kg} /$ $\mathrm{m}^{2}$ is a major risk factor for $\mathrm{DN}$. 


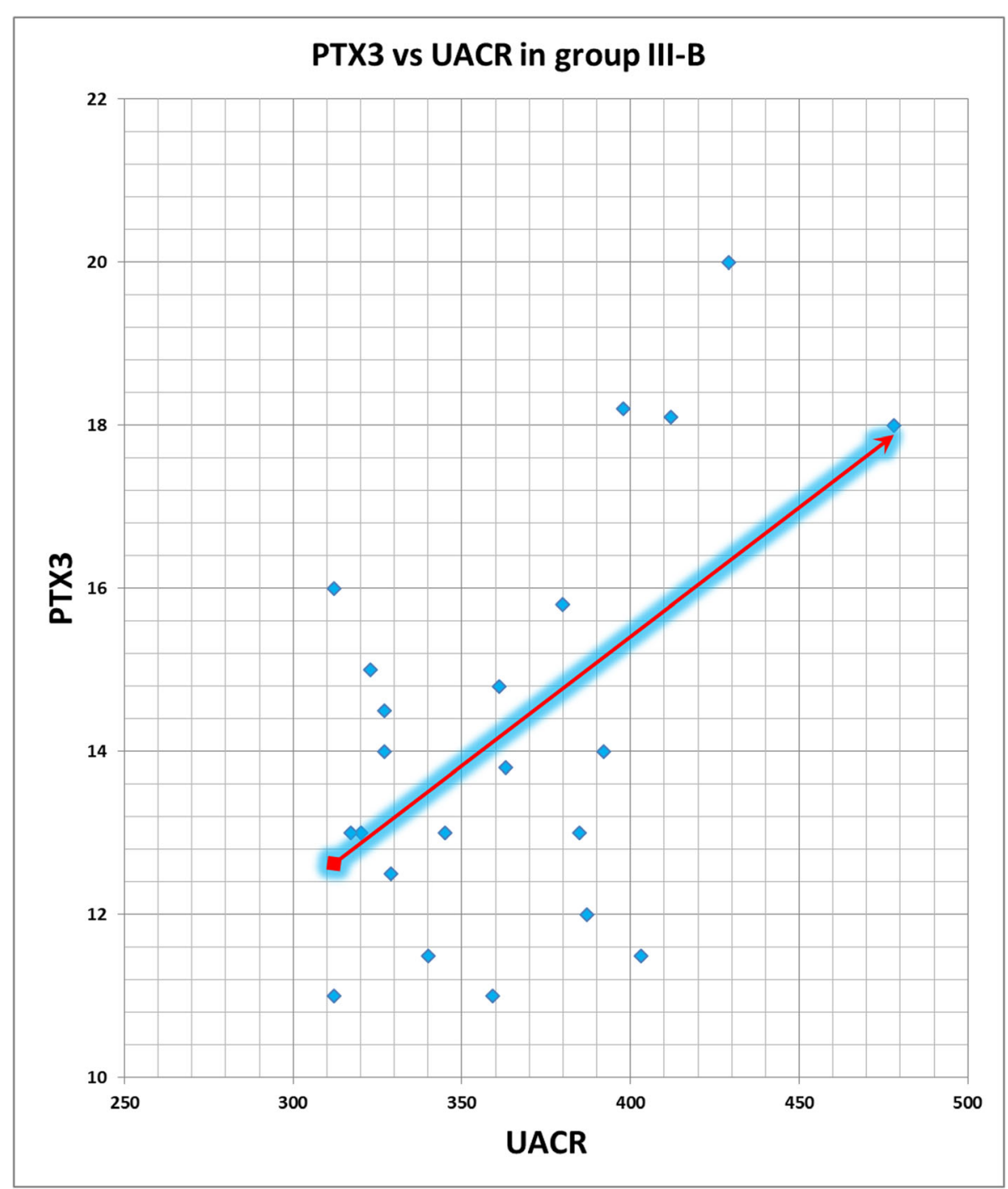

Fig. 3 Positive correlation between PTX3 vs UACR in group III-B

This study showed that patients with DN had longer disease duration than those without DN. Similarly, the incidence of DN is related primarily to the duration and control of diabetes $[12,14,15]$. In accordance with Papademetriou et al. [17], this study showed that duration of $\mathrm{DM}$ and coexisting hypertension remain the most significant risk factors for DN. Moreover, Takao et al. [18] mentioned that control of hypertension significantly reduced the development and progression of DN.

This study also revealed that there was a highly significant correlation between glycemic control $\left(\mathrm{HbA}_{1} \mathrm{c}\right)$ and development of $\mathrm{DN}$ as $\mathrm{HbA}_{1} \mathrm{c}$ was elevated in the $\mathrm{DN}$ groups more than in the control and diabetic without DN groups. These results are in accordance with Takashi et al. [8]. In agreement with Wang et al. [12] and Uzun et al. [9], this study showed that there is a highly significant correlation between FBG and 2hBBPG, and the development of DN. These results are against the observations of Abu Seman et al. [14] who mentioned that there is no significant correlation between FBG and 2hPPBG, and DN.

Furthermore, regarding dyslipidemia, there was a significant correlation between serum TGs and severity of the DN. This is in accordance with Wang et al. [12] and Rutledge et al. [19] who stated that there is a significant association between serum TGs and DN. In contrast to this study, Takashi et al. [8] mentioned that there is no association between serum TGs and DN. However, this study revealed that there was no significant association between the development of DN with serum total cholesterol, HDL, and LDL. Wang et al. [12] and Takashi et al. [8] mentioned that $\mathrm{DN}$ is significantly associated with serum HDL and not significantly associated with total cholesterol and LDL. Uzun et al.'s [9] study 
mentioned that dyslipidemia has no role on the development of DN as there was no significant association between DN and total cholesterol, TG, HDL, and LDL.

In this study, there was a highly significant association between serum creatinine and also UACR, and the development of $\mathrm{DN}$, as they were elevated in the $\mathrm{DN}$ groups more than in the control and diabetic without DN groups. These results are in accordance with Uzun et al. [9], Wang et al. [12], Abu Seman et al. [14], and Sjöberg et al. [15].

Moreover, this study also revealed that there was a highly significant association between DN and serum albumin level as albumin was decreased in the $\mathrm{DN}$ groups more than in the control and diabetic without DN groups. This is in agreement with Uzun et al. [9] and Iwasaki et al. [20]. However, this study revealed that there was no significant difference between the studied groups as regards liver enzyme levels (ALT and AST). This is in agreement with Uzun et al. [9], Wang et al. [12], Abu Seman et al. [14], Sjöberg et al. [15], and Iwasaki et al. [20].

Concerning PTX3, this study revealed that there was a significant increase in its level with the development and progression of DN. PTX3 is higher in the DN groups more than in the control and diabetic without DN groups. Moreover, there was a significant difference between the microalbuminuric and macroalbuminuric groups at a cutoff level of $>10.6 \mathrm{ng} / \mathrm{ml}$. This is in agreement with Uzun et al. [9], Wang et al. [12], and Abu Seman et al. [14] who stated that PTX3 level increases with the development of DN.

According to hs-CRP, this study showed that there was a highly significant increase in its level with the development and progression of DN. hs-CRP was higher in the nephropathy groups more than in the control and diabetes without nephropathy groups. This is in agreement with Wang et al. [12] and Abu Seman et al. [14]. Uzun et al. [9] mentioned that there was no significant difference between the studied groups as regards hsCRP. Furthermore, this study revealed that there was no significant difference, regarding hs-CRP, between DN with microalbuminuria and DN with macroalbuminuria. This is in agreement with Uzun et al. [9], Wang et al. [12], and Abu Seman et al. [14].

So, serum PTX3 can be used as an accurate marker to reveal the progression of $\mathrm{DN}$ and also can differentiate between both microalbuminuric and macroalbuminuric patients.

\section{Conclusions}

Our data suggest that PTX3 can be used as a specific diagnostic and prognostic biomarker of DN prior to the development of overt CKD, and also, it can differentiate between different stages of DN while other routine tests, like hs-CRP, are non-specific and cannot differentiate between different stages of DN. Further studies with a relatively larger sample size are needed to determine the clinical relevance of our findings.

\section{Abbreviations}

ALT: Alanine transaminase; AST: Aspartate transaminase; BMl: Body mass index; CRP: C-reactive protein; CKD: Chronic kidney disease; DM: Diabetes mellitus; DN: Diabetic nephropathy; DBP: Diastolic blood pressure;

ELISA: Enzyme-linked immunosorbent assay; F: ANOVA test; FBG: Fasting blood glucose; HDL: High-density lipoprotein; hs-CRP: High-sensitivity Creactive protein; HS: Highly significant ( $P$ value $<0.001)$; LDL: Low-density lipoprotein; PTX3: Pentraxin 3; 2hPPBG: 2 h postprandial blood glucose; S: Significant ( $P$ value $<0.05)$; SBP: Systolic blood pressure; SD: Standard deviation; T2DM: Type 2 diabetes mellitus; TGs: Triglycerides; UACR: Urinary albumin/creatinine ratio; $X^{2}$ : Chi-square test

\section{Acknowledgements}

Not applicable.

\section{Authors' contributions}

AAA and MAK designed the research. All authors were involved in the protocol development. AAA gained the ethical approval and patient recruitment. TAO and AAA collected the samples. The analysis and interpretation of data were made by MAK, TAO, and AAA. AAA wrote the first draft of the manuscript. All authors reviewed and edited the manuscript and approved the final version of the manuscript.

\section{Funding}

The authors received no financial support for the research, authorship, or publication of this article.

\section{Availability of data and materials}

The datasets used and analyzed during the current study are available from the corresponding author on reasonable request.

\section{Ethics approval and consent to participate}

This study was performed in accordance with the Declaration of Helsinki and approved by the Ethical Committee of Menoufia Faculty of Medicine with an ethics committee reference number 10/2018INTM. A written informed consent was obtained from all participants before the study was commenced.

\section{Consent for publication}

Not applicable.

\section{Competing interests}

The authors declare that they have no competing interests.

\section{Author details}

${ }^{1}$ Faculty of Medicine, Menoufia University, Shebin El-com, Egypt. ${ }^{2}$ Internal Medicine Department, Ahmed Maher Teaching Hospital, Cairo, Egypt.

Received: 23 April 2020 Accepted: 18 June 2020

Published online: 11 August 2020

\section{References}

1. American Diabetes Association (2020) Introduction: standards of medical care in diabetes-2020. Diabetes Care 43:S1-S2. https://doi.org/10.2337/ dc20-Sint

2. Ogurtsova K, da Rocha Fernandes JD, Huang Y, Linnenkamp U, Guariguata L et al (2017) IDF Diabetes Atlas: global estimates for the prevalence of diabetes for 2015 and 2040. Diabetes Res Clin Pract 128:40-50. https://doi. org/10.1016/j.diabres.2017.03.024

3. Koye DN, Magliano DJ, Nelson RG, Pavkov ME (2018) The global epidemiology of diabetes and kidney disease. Adv Chronic Kidney Dis 25: 121-132. https://doi.org/10.1053/j.ackd.2017.10.011

4. Ahn JH, Yu JH, Ko S, Kwon H, Kim DJ, Kim JH et al (2014) Prevalence and determinants of diabetic nephropathy in Korea: Korea National Health and Nutrition Examination Survey. Diabetes Metab J 38:109-119. https://doi.org/ 10.4093/dmj.2014.38.2.109

5. Afkarian M, Zelnick LR, Hall YN, Heagerty PJ, Tuttle K, et al. (2016): Clinical manifestations of kidney disease among us adults with diabetes, 19882014. JAMA, 316:602-610. DOI: https://doi.org/10.1001/jama.2016.10924. 
6. Krolewski AS, Skupien J, Rossin P, Warram JH (2017) Fast renal decline to end-stage renal disease: an unrecognized feature of nephropathy in diabetes. Kidney Int 91:1300-1311. https://doi.org/10.1016/j.kint.2016.10.046

7. Watanabe Y, Yamaguchi T, Ishihara N, Nakamura S, Tanaka S et al (2018) 7 Ketocholesterol induces ROS-mediated mRNA expression of 12lipoxygenase, cyclooxygenase-2 and pro-inflammatory cytokines in human mesangial cells: Potential role in diabetic nephropathy. Prostaglandins Other Lipid Mediat 134:16-23. https://doi.org/10.1016/.jprostaglandins.2017.11.002

8. Takashi Y, Koga M, Matsuzawa Y, Saito J, Omura M et al (2018) Circulating pentraxin 3 is positively associated with chronic hyperglycemia but negatively associated with plasma aldosterone concentration. PLOS ONE 13(5):e0196526. https://doi.org/10.1371/journal.pone.0196526

9. Uzun S, Ozari M, Gursu M, Karadag S, Behlul A et al (2016) Changes in the inflammatory markers with advancing stages of diabetic nephropathy and the role of pentraxin-3. Ren Fail 38:1193-1198. https://doi.org/10.1080/ 0886022X.2016.1209031

10. Shindo A, Tanemura H, Yata K, Hamada K, Shibata M et al (2014) Inflammatory biomarkers in atherosclerosis: pentraxin 3 can become a novel marker of plaque vulnerability. PLoS One 9(6):e100045. https://doi.org/10. 1371/journal.pone.0100045

11. Zhou Y, Ni Z, Zhang J, Zhang W, Wu Q et al (2013) Plasma pentraxin 3 may be a better marker of peripheral artery disease in hemodialysis patients than C-reactive protein. Vasc Med 18:85-91. https://doi.org/10.1177/ $1358863 \times 13483864$

12. Wang R, Zhang J, Hu W (2016) Association of serum pentraxin 3 concentrations with diabetic nephropathy. J Investig Med 64:1124-1127. https://doi.org/10.1136/jim-2016-000082

13. Chen SC, Tseng CH (2013) Dyslipidemia, kidney disease, and cardiovascular disease in diabetic patients. Rev Diabet Stud 10:88-100. https://doi.org/10. 1900/RDS.2013.10.88

14. Abu Seman N, Witasp A, Wan Mohamud WN, Anderstam B, Brismar K et al (2013) Evaluation of the association of plasma pentraxin 3 levels with type 2 diabetes and diabetic nephropathy in a Malay population. J Diabetes Res 2013:298019. https://doi.org/10.1155/2013/298019

15. Sjöberg B, Qureshi AR, Heimbürger O, Stenvinkel P, Lind L et al (2016) Association between levels of pentraxin 3 and incidence of chronic kidney disease in the elderly. J Intern Med 279:173-179. https://doi.org/10.1111/ joim.12411

16. Porrini E, Navarro-Díaz M, Rodríguez-Rodríquez $R$ and Salido E (2019): Renal disease in obesity, metabolic syndrome and diabesity. In: Roelofs JJ, and Vogt L: Diabetic nephropathy, 1st ed, Springer, Cham, PP. 65-80. https://doi. org/10.1007/978-3-319-93521-8_5.

17. Papademetriou V, Zaheer M, Doumas M, Lovato L, Applegate WB et al (2016) Cardiovascular outcomes in action to control cardiovascular risk in diabetes: impact of blood pressure level and presence of kidney disease. Am J Nephrol 43:271-280. https://doi.org/10.1159/000446122

18. Takao T, Matsuyama Y, Yanagisawa H, Kikuchi M, Kawazu S (2014) Visit-tovisit variability in systolic blood pressure predicts development and progression of diabetic nephropathy, but not retinopathy, in patients with type 2 diabetes. J Diabetes Complications 28:185-190. https://doi.org/10. 1016/j.jdiacomp.2013.11.003

19. Rutledge JC, Ng KF, Aung HH, Wilson DW (2010) Role of triglyceride-rich lipoproteins in diabetic nephropathy. Nat Rev Nephrol 6:361-370. https:// doi.org/10.1038/nrneph.2010.59

20. Iwasaki T, Togashi Y, Terauchi Y (2008) Significant association of serum albumin with severity of retinopathy and neuropathy, in addition to that of nephropathy, in Japanese type 2 diabetic patients. Endocr J 55:311-316. https://doi.org/10.1507/endocri.k07-086

\section{Publisher's Note}

Springer Nature remains neutral with regard to jurisdictional claims in published maps and institutional affiliations.

\section{Submit your manuscript to a SpringerOpen ${ }^{\circ}$ journal and benefit from:}

- Convenient online submission

- Rigorous peer review

- Open access: articles freely available online

- High visibility within the field

- Retaining the copyright to your article

Submit your next manuscript at $\boldsymbol{\nabla}$ springeropen.com 